\title{
POTENCIAL FORRAGEIRO DE GENÓTIPOS DE MILHO COM E SEM ESPIGA PRIMÁRIA EM DIFERENTES SISTEMAS DE CULTIVO
}

\author{
Artur Pereira Vasconcelos de Carvalho ${ }^{1}$, Islan Diego Espindula de Carvalho*2, Paulo Vanderlei Ferreira ${ }^{3}$, Douglas
} Ferreira dos Santos ${ }^{4}$, Mariângela Gomes Pereira ${ }^{4}$

\footnotetext{
${ }^{1}$ Eng. Agrônomo, Centro de Ciências Agrárias, Universidade Federal de Alagoas, BR 104 Norte, Km 85, Rio Largo, AL. CEP 57.000-100.

${ }^{2}$ Doutorando em Agronomia (Melhoramento Genético de Plantas), Departamento de Fitotecnia, Universidade Federal Rural de Pernambuco, R. Manuel de Medeiros, s/n - Dois Irmãos, Recife - PE, 52171-900.

${ }_{3}^{3}$ Professor, Centro de Ciências Agrárias (CECA), Universidade Federal de Alagoas, BR 104 Norte, Km 85, Rio Largo, AL. CEP 57.000-100.

${ }^{4}$ Estudante de graduação em Agronomia, Centro de Ciências Agrárias, Universidade Federal de Alagoas, BR 104 Norte, Km 85, Rio Largo, AL. CEP 57.000-100.
}

*Autor para correspondência: Islan Diego Espindula de Carvalho: iislandiego@hotmail.com

RESUMO: O presente trabalho teve como objetivo avaliar o potencial forrageiro de quatro genótipos de milho (Alagoano, Viçosense, Nordestino e Cruzeta), em duas características estruturais da planta (com e sem espiga primária) e em dois sistemas de cultivo (monocultivo e consorciado com feijão, variedade IAC Alvorada). 0 trabalho foi desenvolvido no Centro de Ciências Agrárias da Universidade Federal de Alagoas e foi dividido em dois experimentos, onde no experimento 1 foi realizada a avaliação das plantas de milho utilizando o delineamento experimental em blocos casualizados no esquema fatorial (4x2), com três repetições. Foram avaliadas as variáveis: Produtividade de Matéria Verde da Planta Com a Espiga Primária, Produtividade de Matéria Verde da Planta Sem Espiga Primária, Percentual de Matéria Seca da Planta Com Espiga Primária, Percentual de Matéria Seca da Planta Sem Espiga Primária, Produtividade de Matéria Seca da Planta Com Espiga Primária e Produtividade de Matéria Seca da Planta Sem Espiga Primária. No experimento 2 foi realizada a avaliação da silagem utilizando 0

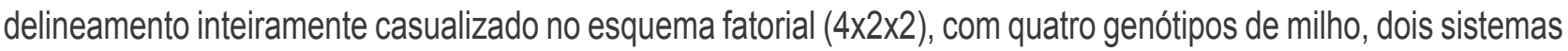
de cultivo e duas características estruturais da planta. Cada parcela experimental foi representada por um silo experimental, constituído de PVC de 0,50 m de comprimento por 0,15 m de diâmetro e volume de 0,00884 $\mathrm{m}^{3}$. As variáveis avaliadas foram: Rendimento de Silagem (RS); Percentual de Matéria Seca da Silagem (\%MSS) e Produtividade de Matéria Seca da Silagem (PMSS). No experimento 1 os genótipos Alagoano, Viçosense e Nordestino apresentaram maiores produtividades de Matéria Verde e Matéria Seca, com médias de 62,60 t ha ${ }^{-1}$, 47,56 t ha-1 ${ }^{-1}$ 25,88 $\mathrm{t} \mathrm{ha}^{-1}$ e 16,37 $\mathrm{t} \mathrm{ha}^{-1}$ para PMVPCEP, PMVPSEP, PMSPCEP e PMSPSEP, respectivamente. No experimento 2 os genótipos Alagoano, Viçosense e Nordestino apresentaram maiores RS e PMSS, com médias de $25,05 \mathrm{t} \mathrm{ha}^{-1}$ e 8,71 tha-1 ${ }^{-1}$, respetivamente. Os sistemas de cultivo não apresentaram diferença significativa pelo teste de Tukey a $5 \%$ de probabilidade e a estrutura da planta com espiga primária se mostrou superior quando comparada sem espiga primária.

PALAVRAS-CHAVE: consórcio; monocultivo; silagem; Zea mays L.

\section{POTENTIAL FORAGE OF MAIZE GENOTYPES WITH AND WITHOUT PRIMARY SPIKE IN DIFFERENT CROPPING SYSTEMS}

\begin{abstract}
The objective of this study was to evaluate the forage potential of four maize genotypes (Alagoano, Viçosense, Nordestino and Cruzeta) in two structural characteristics of the plant (with and without primary spike) and in two cropping systems (monoculture and intercropping with beans, IAC Alvorada variety). The experiment was carried out at the Centro de Ciências Agrárias of the Universidade Federal de Alagoas and was divided in two experiments, where in experiment 1 the evaluation of corn plants was carried out using a randomized complete block design in the factorial scheme $(4 \times 2)$, with three repetition. The following variables were evaluated: Green Matter Productivity of the Primary Spike Plant (PMVPCEP), Green Matter Productivity of the Primary Spike Plant
\end{abstract}


(PMVPSEP), Dry Matter Percentage of the Primary Spike Plant (\% MSPCEP), Dry Matter (\% MSPSEP), Dry Matter Productivity of the Primary Spike Plant (PMSPCEP) and Dry Matter Productivity of the Primary Spike Plant (PMSPSEP). In experiment 2, the evaluation of the silage was carried out using a completely randomized design in the factorial scheme $(4 \times 2 \times 2)$, with four corn genotypes, two cropping systems and two structural characteristics of the plant. Each experimental plot was represented by an experimental silo, composed of PVC $0.50 \mathrm{~m}$ long by $0.15 \mathrm{~m}$ in diameter and $0.00884 \mathrm{~m}^{3}$ in volume. The variables evaluated were: Silage yield (RS); Percentage of Dry Matter of Silage (\% MSS) and Dry Matter Matter Productivity (PMSS). In the experiment 1, the Alagoano, Viçosense and Nordestino genotypes presented higher yields of Dry Matter and Green, with a mean of $62.60 \mathrm{tha}^{-1}$, 47.56 tha ${ }^{-1}, 25.88 \mathrm{tha}^{-1}$ and $16.37 \mathrm{tha}^{-1}$ for PMVPCEP, PMVPSEP, PMSPCEP and PMSPSEP, respectively. In the experiment 2 the genotypes Alagoano, Viçosense and Nordestino presented higher RS and PMSS, with averages of $25.05 \mathrm{t} \mathrm{ha}^{-1}$ and $8.71 \mathrm{t} \mathrm{ha}^{-1}$, respectively. Cultivation systems did not present a significant difference by the Tukey test at $5 \%$ of probability and the structure of the plant with primary spike was superior.

KEYWORDS: Intercropping, Monoculture, Silage, Zea mays L.

\section{INTRODUÇÃO}

A principal fonte de nutrientes para a produção de ruminantes são as pastagens, que por muitas vezes apresentam-se degradadas, com baixo valor nutricional e secas devido ao regime de chuvas da região, inviabilizando sua utilização. Nesse período, uma das alternativas mais viáveis para a suplementação alimentar dos animais é a silagem de milho (Cordeiro e Cequine, 2008).

A silagem é o produto resultante do processo específico de anaerobiose por acidificação de material verde vegetal, por ação de bactérias epíficas ácido láticas que vivem na planta hospedeira em simbiose natural, e que convertem carboidratos solúveis em ácidos orgânicos, principalmente 0 ácido lático, 0 que resulta em queda do $\mathrm{pH}$ e a forragem é então preservada (Kim e Adesogan, 2006). O milho é considerado a cultura padrão para produção de silagem devido a seu valor nutritivo e sua elevada produtividade, suprindo exigências dos rebanhos mais exigentes (Aguiar et al., 2014).

A silagem de milho é o principal volumoso utilizado nos sistemas intensivos de produção de carne e, principalmente, de leite e a área de lavoura destinada à produção de silagem é de aproximadamente 2,25 milhões de hectares, em torno de $15 \%$ da área total cultivada de milho no Brasil (MAPA, 2013). As maiores áreas de produção de silagem de milho no Brasil se encontram nas regiões sul e sudeste, devido à alta concentração de bacias leiteiras e maiores produções de leite (Pereira, 2013).

Na região Nordeste, Alagoas é um dos Estados mais tradicionais na produção de leite e no sertão alagoano, mesorregião com a maior produção leiteira do Estado, a suplementação volumosa é dividida entre silagem de milho e palma forrageira, enquanto no leste alagoano, mesorregião submetida a um regime climático de menor risco, a silagem de milho é o principal suplemento volumoso fornecido aos animais durante o período seco (Oliveira et al., 2006).

Tradicionalmente, os genótipos de milho de alta produção de grãos são recomendados como mais adequados para produção de ensilados de alta qualidade. Para uma produção de silagem de milho de alta qualidade deve-se levar em consideração não somente a produção de grãos, mas também os demais componentes da planta como um todo (Silva Júnior et al., 2015). Desta forma, existe a necessidade de conhecer 0 desempenho de cultivares nas mais diferentes condições ambientais em relação à produção e qualidade da silagem (Oliveira et al., 2006).

Em uma comunidade vegetal com diferentes sistemas de cultivo, homogêneo ou consorciado, as plantas estão sujeitas a diversos tipos de interações (Teixeira et al., 2005). O plantio do feijão em consórcio com outras culturas se tornou comum no Brasil, principalmente entre os pequenos produtores, devido à capacidade das leguminosas de disponibilizar $\mathrm{N}$ no solo, podendo beneficiar a cultura do milho (Costa e Silva, 2008).

Em Alagoas o cultivo do milho é predominantemente consorciado, com destaque para o sistema de consórcio com a cultura do feijão. Além de variedades improdutivas nas condições ambientais do Estado, o baixo nível tecnológico, a falta de conhecimento técnico-científico por parte dos produtores e a ausência de cultivares adaptadas ao sistema de cultivo consorciado justificam o baixo 
rendimento da cultura (Cuenca et al., 2005; Madalena et al., 2009).

Diante disso, o presente trabalho teve como objetivo avaliar o potencial forrageiro de quatro genótipos de milho com e sem espiga primária em diferentes sistemas de cultivo.

\section{MATERIAL E MÉTODOS}

Os experimentos foram conduzidos nas dependências do Setor de Melhoramento Genético de Plantas do Centro de Ciências Agrárias da Universidade Federal de Alagoas (SMGP/CECA/UFAL) - Campus Delza Gitaí, BR 104 Norte, km 85, situado no Município de Rio Largo, Estado de Alagoas, localizada a $9^{\circ} 27^{\prime}$ de latitude sul e $35^{\circ} 27^{\prime}$ de longitude oeste e $127 \mathrm{~m}$ de altitude. A região apresenta clima quente e úmido, totais pluviométricos anuais elevados (1.500 - $2.000 \mathrm{~mm}$ ), com o período chuvoso concentrado no outono-inverno, onde a precipitação equivale a $70 \%$ do total anual, e o período seco na primavera-verão apresentando déficits hídricos elevados (Souza et al., 2004). 0 experimento 1 foi conduzido no período de agosto a novembro de 2014 na área experimental do SMGP, cujo o solo é classificado como Latossolo Amarelo coeso argissólico, de textura franca arenosa (Santos, 2006). O Experimento 2 foi conduzido no laboratório do SMGP/CECA/UFAL, de novembro de 2014 a janeiro de 2015.

No experimento 10 delineamento experimental utilizado foi em blocos casualizados no esquema fatorial $(4 \times 2)$, com oito tratamentos constituídos pela combinação entre quatro genótipos de milho (Alagoano, Viçosense, Nordestino e Cruzeta) e dois sistemas de cultivo: monocultivo e consorciado com feijão (Phaseolus vulgaris L.), variedade IAC Alvorada. $\mathrm{O}$ experimento foi dividido em três blocos, totalizando 24 parcelas experimentais. As parcelas com milho em monocultivo (Figura 01) tiveram quatro fileiras de plantas com 5,0 m de comprimento, espaçadas a 1,0 $m$ entre linhas e 0,2 m entre plantas, com uma planta por cova, constituindo uma população de milho de 50.000 plantas.ha $^{-1}$. As parcelas consorciadas (Figura 1) tiveram as mesmas dimensões, porém nas entre linhas de milho tiveram duas fileiras de plantas de feijão de $5,0 \mathrm{~m}$ de comprimento, espaçadas a 0,4 m entre linhas e 0,3 m entre plantas, com duas plantas por cova, constituindo uma população de feijão de 113.333 plantas ha1 mais 50.000 plantas de milho.
No experimento dois foi utilizado 0 delineamento inteiramente casualizado no esquema fatorial (4 $\times 2 \times 2)$, com 16 tratamentos constituídos pela combinação entre quatro genótipos de milho (Alagoano, Viçosense, Nordestino e Cruzeta), dois sistemas de cultivo (monocultivo e consorciado) e duas características estruturais da planta (com e sem a espiga primária). 0 experimento teve três repetições, totalizando 48 parcelas.

Os genótipos utilizados apresentam prolificidade, dessa forma a espiga principal foi retirada da unidade experimental correspondente, restando as demais espigas na planta. Aespiga principal das plantas do tratamento sem a espiga principal foi retirada no dia da colheita. Os genótipos no momento da colheita para a produção de silagem apresentaram alturas variáveis de acordo com as características de cada genótipos, com variação de 1,7 a 2,8 m.

Cada parcela experimental foi representada por um silo experimental, constituído de um cano de PVC de $0,50 \mathrm{~m}$ de comprimento por $0,15 \mathrm{~m}$ de diâmetro e volume de 0,00884 $\mathrm{m}^{3}$.

Antes do plantio foi realizada uma amostragem de solo para análise das condições químicas, através da Empresa Central Analítica de Maceió, cujos resultados foram os seguintes: $\mathrm{pH}-5,4$; $\mathrm{Na}-23 \mathrm{ppm}$; P - 55 ppm; K - 37 ppm; Ca+mg 5,6 meq/100ml; Ca - 3,2 meq/100; Mg - 2,4 meq/100; Al 0,03 meq/100; $\mathrm{H}+\mathrm{Al}-3,6 \mathrm{meq} / 100 ;$ S.B. $-5,8$ meq/100; CTC - 9,4 meq/100; V - 61,7\%; m 0,5\% e M.0. 2,13\%. Também foi realizada análise do esterco ovino/caprino utilizado na adubação em fundação na ocasião do plantio, tendo como resultados: $\mathrm{pH}-7,9$; Umidade $\left(65^{\circ} \mathrm{C}\right)-8,7 \%$; Carbono orgânico - 34,7; $\mathrm{N}$ total - 1,80\%; Relação C:N - 20\%; P2 O5 total - 1,40\%; K2 O - 2,24\%; S - 0,23\%; $\mathrm{Ca}-0,9$ meq/100; $\mathrm{Mg}-0,4 \mathrm{meq} / 100$.

0 preparo do solo ocorreu manualmente com uso de enxadas e logo após foram abertos os sulcos com cerca de 10 centímetros de profundidade, onde foi aplicado o esterco ovino/caprino e incorporado dentro do sulco, sendo aplicadas 10 t ha-1 para o milho e oito t ha-1 para o feijão.

O plantio ocorreu no dia 20 de agosto de 2014, sendo semeadas manualmente três sementes por cova de cada cultura, ambas com profundidades de três a quatro centímetros, e 10 dias após foi realizado 0 desbaste. As fileiras de plantas ficaram no sentido leste-oeste. 
O controle de plantas daninhas foi realizado com duas capinas manuais com enxada realizada aos 15 e 35 dias após o plantio. Foi observado no milho 0 ataque da praga Spodoptera frugiperda, conhecida como Lagarta-do-Cartucho, e o controle foi realizado com duas pulverizações do inseticida Connect $\circledast$ (700 ml.ha-1 ${ }^{-1}$ aos 15 e 30 dias, e uma aplicação do inseticida Capataz ${ }^{\circledR}\left(500\right.$ ml.ha $\left.^{-1}\right)$ aos 50 dias após o plantio, sendo ambos aplicados com pulverizador costal com capacidade de 20 litros utilizando o bico tipo leque $\left(105^{\circ}\right)$.

Para a manutenção das condições hídricas do solo e ideal desenvolvimento das culturas, foi instalado um sistema de irrigação por aspersão, com lâmina diária de $7 \mathrm{~mm}$, sendo aplicados nos veranicos durante a condução do experimento. De acordo com a Estação Meteorológica do CECA/ UFAL, durante a condução do experimento os dados meteorológicos foram: Precipitação: 153,7; 135,9; 229,4 e $48,36 \mathrm{~mm}$, do mês de agosto a novembro de 2015 , temperatura média nos meses de $23,55^{\circ} \mathrm{C}$, média mínima $18,77^{\circ} \mathrm{C}$, média máxima $30,07^{\circ} \mathrm{C}$ e umidade relativa do ar de $80,1 \%$.

Foram consideradas como área útil as duas fileiras centrais de milho de cada parcela, uma fileira formada de plantas de milho com a presença da espiga primária e outra formada por plantas de milho com a ausência da espiga primária, sendo eliminadas as duas plantas de cada extremidade.

As plantas da área útil de cada parcela foram cortadas a $20 \mathrm{~cm}$ do solo aos 85 dias após o plantio. Foi colhida uma fileira com a presença da espiga primária e outra fileira sem a espiga primária, cinco plantas de cada tratamento foram pesadas para determinação da matéria verde e, posteriormente, juntas com as demais foram trituradas em uma máquina forrageira. Em seguida, foi coletada amostra de $1 \mathrm{~kg}$ do material triturado de cada tratamento e posteriormente secada em estufa a $105^{\circ}$ até peso constante para determinação da matéria seca da planta.

Após colhidas as plantas da área útil de cada parcela do experimento 1 , as mesmas foram trituradas em máquina forrageira e todo material triturado foi depositado em silo experimental, constituído de PVC com peso médio de $0,885 \mathrm{~kg}, 0,50 \mathrm{~m}$ de comprimento por $0,15 \mathrm{~m}$ de diâmetro e volume de $0,00884 \mathrm{~m}^{3}$, e compactado manualmente até completar sua capacidade. Em seguida o silo experimental foi vedado com lona de polietileno.

Setenta dias depois de vedados, cada silo experimental foi pesado e aberto, desprezaram-se as porções iniciais de cada extremidade do silo e retirada uma amostra de $400 \mathrm{~g}$ de cada tratamento da parte intermediária, onde foram levadas para secagem em estufa a $105^{\circ}$ até peso constante, para posterior determinação da matéria seca da silagem.

As variáveis avaliadas no experimento 1 foram as seguintes:

Produtividade de Matéria Verde da Planta Com Espiga Primária (PMVPCEP em $t$ ha ${ }^{-1}$ ): determinada a partir da pesagem de cinco plantas da área útil;

Produtividade de Matéria Verde da Planta Sem Espiga Primária (PMVPSEP em $\mathrm{t} \mathrm{ha}^{-1}$ ): determinada a partir da pesagem de cinco plantas da área útil;

Percentual de Matéria Seca da Planta Com Espiga Primária (\%MSPCEP): determinada a partir da relação entre o peso da matéria verde e da matéria seca (em estufa a $105^{\circ}$ por $24 \mathrm{~h}$ ) da amostra coletada;

Percentual de Matéria Seca da Planta Sem Espiga Primária (\%MSPSEP): determinada a partir da relação entre o peso da matéria verde e da matéria seca (em estufa a $105^{\circ}$ por $24 \mathrm{~h}$ ) da amostra coletada.

Produtividade de Matéria Seca da Planta Com Espiga Primária (PMSPCEP em t ha ${ }^{-1}$ ): determinada a partir da relação entre a Produtividade de Matéria Verde da Planta e o Percentual de Matéria Seca da Planta.

Produtividade de Matéria Seca da Planta Sem Espiga Primária (PMSPSEP em $t$ ha ${ }^{-1}$ ): determinada a partir da relação entre a Produtividade de Matéria Verde da Planta e o Percentual de Matéria Seca da Planta.

As variáveis avaliadas no experimento 2 foram as seguintes:

Rendimento de silagem (RS em $t \mathrm{ha}^{-1}$ ): determinada através da relação entre o peso final da silagem (70 dias após vedado o silo), o número de plantas trituradas até completar o silo e o número de plantas por hectare, sendo então calculado por meio da equação: $R S=\left(N^{\circ}\right.$ de Plantas ha ${ }^{-1} \times$ Peso da Amostra (kg)) / Nº de Plantas da Amostra.

Percentual de Matéria Seca da Silagem (\%MSS): determinado a partir da relação entre o peso da amostra coletada após abertura do silo (400 g) e a matéria seca da mesma; 
Produtividade de Matéria Seca da Silagem (PMSS em tha-1): determinado a partir da relação entre Rendimento de Silagem e Percentual da Matéria Seca da Silagem.

As análises de variância dos experimentos 1 e 2 foram realizadas seguindo as recomendações de Ferreira (2000). As médias dos caracteres avaliados para os sistemas de cultivo (Experimentos 1 e 2) e para as características estruturais da planta (Experimento 2) foram comparadas pelo Teste $\mathrm{F}$ a $5 \%$ de probabilidade, enquanto que os genótipos de milho (Experimentos 1 e 2) foram comparados pelo teste de Tukey a $5 \%$ de probabilidade utilizando 0 aplicativo Sisvar (Ferreira, 2003).

\section{RESULTADOS E DISCUSSÃO}

$\mathrm{Na}$ Tabela 1 encontram-se os resultados das análises de variância e coeficientes de variação do experimento 1 na avaliação do potencial forrageiro de genótipos de milho em diferentes sistemas de cultivo, para as seguintes variáveis: Produtividade de Matéria Verde da Planta Com a Espiga Primária (PMVPCEP); Produtividade de Matéria Verde da Planta Sem Espiga Primária (PMVPSEP); Percentual de Matéria Seca da Planta Com Espiga Primária (\%MSPCEP); Percentual de Matéria Seca daPlantaSemEspiga Primária(\%MSPSEP); Produtividade de Matéria Seca da Planta Com Espiga Primária (PMSPCEP) e Produtividade de Matéria Seca da Planta Sem Espiga Primária (PMSPSEP).

Tabela 1. Resumo das análises de variância e coeficientes de variação para os caracteres avaliados no potencial forrageiro de genótipos de milho em diferentes sistemas de cultivo. Rio Largo-AL, 2015/2016.

\begin{tabular}{|c|c|c|c|c|c|c|c|}
\hline \multirow[b]{2}{*}{ Fonte de Variação } & \multirow[b]{2}{*}{$\mathrm{GL}$} & \multicolumn{6}{|c|}{ QM } \\
\hline & & $\begin{array}{c}\text { PMVPCEP } \\
\left(\text { t.ha }^{-1}\right)\end{array}$ & $\begin{array}{c}\text { PMVPSEP } \\
\left(\text { t.ha }^{-1}\right)\end{array}$ & $\begin{array}{c}\% \\
\text { MSPCEP }\end{array}$ & $\begin{array}{c}\% \\
\text { MSPSEP }\end{array}$ & $\begin{array}{c}\text { PMSPCEP } \\
\text { (t.ha-1) }\end{array}$ & $\begin{array}{c}\text { PMSPSEP } \\
\text { (t.ha-1) }\end{array}$ \\
\hline Genótipos (G) & 3 & $1415,5810^{* *}$ & $771,0645^{\star *}$ & $0,1999^{\text {ns }}$ & $0,0896^{\text {ns }}$ & $168,1600^{* *}$ & $69,6719^{\text {ns }}$ \\
\hline Sist. Cultivo (S) & 1 & $306,6635^{\text {ns }}$ & $82,3251^{\text {ns }}$ & $0,0032^{\text {ns }}$ & $0,0047^{\text {ns }}$ & $50,4600^{\text {ns }}$ & $8,7242^{\text {ns }}$ \\
\hline$G \times S$ & 3 & $151,8604^{\text {ns }}$ & $48,9917^{\text {ns }}$ & $0,1205^{\text {ns }}$ & $0,2436^{\text {ns }}$ & $35,6196^{\mathrm{ns}}$ & $3,9044^{\text {ns }}$ \\
\hline Blocos & 2 & 2440,6463 & 1294,2304 & 3,3251 & 2,4473 & 86,6115 & 40,9138 \\
\hline Resíduo & 14 & 154,2096 & 83,0208 & 0,1656 & 0,1484 & 16,6965 & 9,2092 \\
\hline TOTAL & 23 & & & & & & \\
\hline C.V. $(\%)$ & - & 22,55 & 21,72 & 6,32 & 6,55 & 18,63 & 21,58 \\
\hline
\end{tabular}

**: Diferença significativa a $1 \%$ de probabilidade pelo teste F; ns: Não significativo a $5 \%$ de probabilidade pelo teste $\mathrm{F}$. PMVPCEP: Produtividade de Matéria Verde da Planta Com a Espiga Primária; PMVPSEP: Produtividade de Matéria Verde da Planta Sem Espiga Primária; \%MSPCEP: Percentual de Matéria Seca da Planta Com Espiga Primária; \%MSPSEP: Percentual de Matéria Seca da Planta Sem Espiga Primária; PMSPCEP: Produtividade de Matéria Seca da Planta Com Espiga Primária; PMSPSEP: Produtividade de Matéria Seca da Planta Sem Espiga Primária.

De acordo com o teste $F$, a fonte de variação genótipos apresentou diferença significativa a $1 \%$ de probabilidade paras as variáveis PMVPCEP, PMVPSEP e PMSPCEP, enquanto que para as demais variáveis não houve diferença significativa a $5 \%$ de probabilidade. Para a fonte de variação sistemas de cultivo e a interação $\mathrm{G}$ x S não houve diferença significativa a 5\% de probabilidade para todas as variáveis.

Os coeficientes de variação apresentaram ótima precisão experimental para as variáveis \%MSPCEP $(6,32 \%)$ e $\%$ MSPSEP (6,55\%), enquanto quePMSPCEP $(18,63 \%)$ uma precisão experimental aceitável. As variáveis PMVPCEP (22,55\%), PMVPSEP (21,72\%) e PMSPSEP (21,58\%) apresentaram coeficientes de variação elevados. Variáveis relacionadas com produção e rendimento sofrem muita influência do ambiente, justificando seus elevados coeficientes de variação (Ferreira, 2000).

$\mathrm{Na}$ Tabela 2 encontram-se as comparações das médias dos quatro genótipos de milho para as variáveis: Produtividade de Matéria Verde da Planta Com a Espiga Primária (PMVPCEP), Produtividade de Matéria Verde da Planta Sem Espiga Primária (PMVPSEP), Percentual de Matéria Seca da Planta Com Espiga Primária (\%MSPCEP), Percentual de Matéria Seca da Planta Sem Espiga Primária (\%MSPSEP), Produtividade de Matéria Seca da Planta Com Espiga Primária (PMSPCEP) e Produtividade de Matéria Seca da Planta Sem Espiga Primária (PMSPSEP), avaliadas pelo Teste de Tukey a $5 \%$ de probabilidade. 
Tabela 2. Médias dos genótipos para os caracteres avaliados no potencial forrageiro de quatro genótipos de milho. Rio Largo-AL, 2015/2016.

\begin{tabular}{ccccccc}
\hline Genótipos & $\begin{array}{c}\text { PMVPCEP } \\
\left(\text { t.ha }{ }^{-1}\right)\end{array}$ & $\begin{array}{c}\text { PMVPSEP } \\
(\text { t.ha-1) }\end{array}$ & $\begin{array}{c}\% \\
\text { MSPCEP }\end{array}$ & $\begin{array}{c}\% \\
\text { MSPSEP }\end{array}$ & $\begin{array}{c}\text { PMSPCEP } \\
(\text { t.ha-1) }\end{array}$ & $\begin{array}{c}\text { PMSPSEP } \\
\left(\text { t.ha- } a^{-1}\right)\end{array}$ \\
\hline Alagoano & $65,33 \mathrm{a}$ & $45,44 \mathrm{a}$ & $39,26^{\mathrm{a}}$ & $33,11 \mathrm{a}$ & $25,64^{\mathrm{a}}$ & $15,04^{\mathrm{a}}$ \\
\hline Viçosense & $63,97 \mathrm{a}$ & $49,01 \mathrm{a}$ & $40,85^{\mathrm{a}}$ & $34,90 \mathrm{a}$ & $26,13^{\mathrm{a}}$ & $17,10^{\mathrm{a}}$ \\
\hline Nordestino & $58,51 \mathrm{a}$ & $48,23 \mathrm{a}$ & $44,26^{\mathrm{a}}$ & $35,23 \mathrm{a}$ & $25,89^{\mathrm{a}}$ & $16,99^{\mathrm{a}}$ \\
\hline Cruzeta & $32,45 \mathrm{~b}$ & $25,10 \mathrm{~b}$ & $43,30^{\mathrm{a}}$ & $36,34 \mathrm{a}$ & $14,05 \mathrm{~b}$ & $9,12 \mathrm{~b}$ \\
\hline Média & & & 41,91 & 34,89 & & \\
\hline$\Delta(5 \%)$ & 20,84 & 15,29 & 8,63 & 7,69 & 6,85 & 5,09 \\
\hline
\end{tabular}

Médias seguidas pela mesma letra nas colunas não diferem estatisticamente entre si pelo teste de Tukey a $5 \%$ de probabilidade. PMVPCEP: Produtividade de Matéria Verde da Planta Com a Espiga Primária; PMVPSEP: Produtividade de Matéria Verde da Planta Sem Espiga Primária; \%MSPCEP: Percentual de Matéria Seca da Planta Com Espiga Primária; \%MSPSEP: Percentual de Matéria Seca da Planta Sem Espiga Primária; PMSPCEP: Produtividade de Matéria Seca da Planta Com Espiga Primária; PMSPSEP: Produtividade de Matéria Seca da Planta Sem Espiga Primária.

Os genótipos Alagoano, Viçosense e Nordestino apresentaram em grande parte das plantas, além da espiga primária, espigas de menor porte (espigas refugo), que apesar de não apresentarem importância econômica para grãos, são de extrema importância para produção de silagem no enriquecimento de seu valor nutricional. A variedade Cruzeta apresentou somente a espiga primária. A prolificidade é uma característica inerente à constituição genética de cada genótipo, porém as espigas secundárias só apresentam grande desenvolvimento em ótimas situações de cultivo (Sangoi et al., 2010).

Além de ser um parâmetro para dimensionamentos de silos, a produção de matéria verde da planta é um dos primeiros parâmetros a avaliar quando se busca informações sobre determinada cultivar, sendo, portanto, uma preocupação anterior aos parâmetros de qualidade da silagem (Ferrari Júnior et al., 2005). Os genótipos do SMGP apresentaram maiores produtividades de matéria verde da planta em relação à variedade Cruzeta, tanto com a presença da espiga primária, como sem espiga primária.

Os genótipos Alagoano (65,33 tha $\left.{ }^{-1}\right)$, Viçosense $\left(63,97\right.$ t ha $\left.^{-1}\right)$ e Nordestino $\left(58,51 \mathrm{t} \mathrm{ha}^{-1}\right)$ se mostraram semelhantes estatisticamente e apresentaram as maiores PMVPCEP quando comparadas com a variedade Cruzeta $\left(32,45\right.$ t ha $\left.^{-1}\right)$.

Para PMVPSEP os genótipos Viçosense $(49,01$ t ha $\left.{ }^{-1}\right)$, Nordestino $\left(48,23\right.$ t ha $\left.^{-1}\right)$ e Alagoano (45,44 t ha $\left.{ }^{1}\right)$ não diferiram estatisticamente e foram superiores a variedade Cruzeta $\left(25,10\right.$ t ha $\left.^{-1}\right)$.
A matéria seca caracteriza-se como fator de grande importância na composição bromatológica da planta, pois é a porção do alimento onde está concentrado todo seu valor nutritivo e a partir dela determina-se a produtividade de cada nutriente que será importante no desenvolvimento do animal (Dupont, 2016).

Os genótipos Viçosense $\left(26,13 \mathrm{t} \mathrm{ha}^{-1}\right)$, Nordestino $\left(25,89 \mathrm{t} \mathrm{ha}^{-1}\right)$ e Alagoano $\left(25,64 \mathrm{t} \mathrm{ha}^{-}\right.$ 1) não diferiram estatisticamente e apresentaram maior PMSPCEP em relação à variedade Cruzeta $\left(14,05\right.$ t ha $\left.^{-1}\right)$.

Em relação à variável PMSPSEP, não houve diferença significativa para os genótipos Viçosense $\left(17,10 \mathrm{t} \mathrm{ha}^{-1}\right)$, Nordestino $\left(16,99 \mathrm{t} \mathrm{ha}^{-1}\right)$ e Alagoano $\left(15,04 \mathrm{t} \mathrm{ha}^{-1}\right)$, porém foram superiores ao genótipo Cruzeta $\left(9,12\right.$ t ha $\left.^{-1}\right)$.

A Cruzeta apresentou resultados inferiores em comparação aos três outros genótipos em função de suas características genotípicas, além da adaptação ao ambiente, vez que o genótipo Cruzeta foi desenvolvido em outras regiões diferentes desse cultivo experimental, diferentemente dos outros três genótipos que foram desenvolvidos na região do estudo, além do menor porte da variedade cruzeta.

A produtividade de silagem de milho será decorrente de fatores relativos à escolha do material genético, do plantio e da condução da cultura e quanto maior for a produtividade menor será 0 custo de produção. Produções acima de $51 \mathrm{t} \mathrm{ha}^{-1}$ de matéria verde e $17 \mathrm{t} \mathrm{ha}^{-1}$ de matéria seca são consideradas 
altas (Shmidt, 2011). Para as variáveis PMVPCEP e PMSPCEP os genótipos Alagoano, Viçosense e Nordestino ultrapassam os limites de produtividade de matéria verde e seca propostos pelo referido autor. Para PMSPSEP o genótipo Viçosense apresentou resultado superior a $17 \mathrm{t} \mathrm{ha}^{-1}$, indicando o potencial forrageiro do genótipo mesmo sem a presença da espiga primária.

Os genótipos do SMGP (Alagoano, Viçosense e Nordestino) quando comparados com resultados obtidos por Cordeiro e Cequine (2008) em avaliação de híbridos de milho para produção de silagem, e Turco (2011) em avaliação de híbrido de milho em alto nível de adubação, apresentaram-se superiores para matéria verde e matéria seca com a espiga primária presente na planta. Mesmo sem a espiga primária na planta, os genótipos do SMGP apresentaram resultados semelhantes para matéria verde e matéria seca quando comparados com os referidos autores, mostrando que tais genótipos apresentam potencial forrageiro mesmo sem a espiga primária, podendo beneficiar 0 produtor com ganhos econômicos não somente através da espiga comercial, como também realizando 0 aproveitamento da planta para forragem.
Para as variáveis \%MSPCEP e \%MSPSEP não houve diferença significativa para todos os genótipos avaliados, com médias gerais de 41,91 e 34,89\%, respectivamente. De acordo com Lauer (1996), teores de matéria seca da plantaabaixo de $30 \%$ estariam relacionados com menor produção de matéria seca, perdas de matéria seca por lixiviação, baixa qualidade da silagem e redução no consumo por animais. Nenhum dos genótipos avaliados apresentou plantas com teores de matéria seca abaixo de $30 \%$, seja com espiga primária ou sem.

$\mathrm{Na}$ Tabela 3 encontram-se as comparações das médias dos dois sistemas de cultivos avaliados, monocultivo e consorciado, para as variáveis: Produtividade de Matéria Verde da Planta Com a Espiga Primária (PMVPCEP), Produtividade de Matéria Verde da Planta Sem Espiga Primária (PMVPSEP), Percentual de Matéria Seca da Planta Com Espiga Primária (\%MSPCEP), Percentual de Matéria Seca da Planta Sem Espiga Primária (\%MSPSEP), Produtividade de Matéria Seca da Planta Com Espiga Primária (PMSPCEP) e Produtividade de Matéria Seca da Planta Sem Espiga Primária (PMSPSEP), avaliadas pelo teste $\mathrm{F}$ a $5 \%$ de probabilidade.

Tabela 3. Médias dos sistemas de cultivo para os caracteres avaliados no potencial forrageiro de quatro genótipos de milho. Rio Largo-AL, 2015/2016.

\begin{tabular}{ccccccc}
\hline Sistema de cultivo & $\begin{array}{c}\text { PMVPCEP } \\
(\text { t.ha-1 })\end{array}$ & $\begin{array}{c}\text { PMVPSEP } \\
(\text { t.ha-1 })\end{array}$ & $\begin{array}{c}\% \\
\text { MSPCEP }\end{array}$ & $\begin{array}{c}\% \\
\text { MSPSEP }\end{array}$ & $\begin{array}{c}\text { PMSPCEP } \\
\left(\text { t.ha }{ }^{-1}\right)\end{array}$ & $\begin{array}{c}\text { PMSPSEP } \\
\left(\text { t.ha }^{-1}\right)\end{array}$ \\
\hline Monocultivo & $58,64 a$ & $40,09 a$ & $41,66 a$ & $34,71 a$ & $24,42^{a}$ & $13,91 a$ \\
\hline Consórcio & $51,49 a$ & $43,80 a$ & $42,18 a$ & $35,08 a$ & $21,71^{a}$ & $15,36 a$ \\
\hline Média & 55,06 & 41,94 & 41,92 & 34,89 & 23,06 & 14,63 \\
\hline
\end{tabular}

Médias seguidas pela mesma letra nas colunas não diferem estatisticamente entre si pelo teste $F$ a $5 \%$ de probabilidade. PMVPCEP: Produtividade de Matéria Verde da Planta Com a Espiga Primária; PMVPSEP: Produtividade de Matéria Verde da Planta Sem Espiga Primária; \%MSPCEP: Percentual de Matéria Seca da Planta Com Espiga Primária; \%MSPSEP: Percentual de Matéria Seca da Planta Sem Espiga Primária; PMSPCEP: Produtividade de Matéria Seca da Planta Com Espiga Primária; PMSPSEP: Produtividade de Matéria Seca da Planta Sem Espiga Primária.

Não houve diferença significativa para todas as variáveis em relação aos dois sistemas de cultivos avaliados, com médias gerais de 55,06 tha

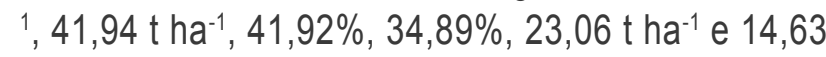
$\mathrm{t}$ ha $^{-1}$ para as respectivas variáveis: PMVPCEP, PMVPSEP, \%MSPCEP, \%MSPSEP, PMSPCEP e PMSPSEP. Os resultados mostram que os sistemas de cultivo não influenciaram no potencial forrageiro dos genótipos de milho.
A utilização do consórcio mesmo aumentando a densidade de plantas na área o que aumenta a competição por fatores de crescimento, proporciona também algumas vantagens como a fixação biológica de nitrogênio promovida pela simbiose entre o feijão e microrganismos, menor evaporação de água no solo, menor influência de plantas daninhas na produtividade, diminuição da ocorrência de pragas, entre outras vantagens, dessa 
forma houve uma compensação em relação ao monocultivo do milho, fato que fez com que os dois sistemas apresentassem resultados semelhantes (Estênio, 2014).

Na Tabela 4 encontram-se os resultados das análises de variância e coeficientes de variação do experimento 2 na avaliação do potencial forrageiro de genótipos de milho em diferentes sistemas de cultivo com e sem espiga primária, para as seguintes variáveis: Rendimento de Silagem (RS); Percentual de Matéria Seca da Silagem (\%MSS) e Produtividade de Matéria Seca da Silagem (PMSS).

Tabela 4. Resumo das análises de variância e coeficientes de variação para os caracteres avaliados no potencial forrageiro de genótipos de milho com e sem espiga primária em diferentes sistemas de cultivos. Rio Largo-AL, 2015/2016.

\begin{tabular}{|c|c|c|c|c|}
\hline \multirow{2}{*}{ Fonte de Variação } & \multirow{2}{*}{ GL } & \multicolumn{3}{|c|}{ QM } \\
\hline & & RS (t.ha $\left.a^{-1}\right)$ & $\% \mathrm{MSS}$ & PMSS (t.ha- $\left.{ }^{-1}\right)$ \\
\hline Genótipos (G) & 3 & $449,0793^{* *}$ & $0,0997^{\mathrm{ns}}$ & $54,8335^{* *}$ \\
\hline Características Estruturais da Planta (C) & 1 & $109,2636^{* *}$ & $1,0262^{\star \star}$ & $40,9036^{* *}$ \\
\hline Sistemas Cultivo (S) & 1 & $1,8252^{\text {ns }}$ & $0,0461^{\text {ns }}$ & $0,0143^{\text {ns }}$ \\
\hline GXS & 3 & $14,0189^{\text {ns }}$ & $0,1640^{\text {ns }}$ & $0,4615^{\text {ns }}$ \\
\hline GXC & 3 & $10,8753^{\text {ns }}$ & $0,2119^{\text {ns }}$ & $0,9929^{\text {ns }}$ \\
\hline$S \times C$ & 1 & $30,8802^{\text {ns }}$ & $0,1986^{\text {ns }}$ & $1,2772^{\mathrm{ns}}$ \\
\hline GXSXC & 3 & $15,3000^{\text {ns }}$ & $0,0633^{\text {ns }}$ & $1,4849^{\text {ns }}$ \\
\hline Blocos & 2 & 447,5852 & 2,0197 & 13,8044 \\
\hline Resíduo & 30 & 14,8987 & 0,0905 & 2,4853 \\
\hline TOTAL & 47 & & & \\
\hline C.V. $(\%)$ & & 17,53 & 5,08 & 20,61 \\
\hline
\end{tabular}

**: Diferença significativa a $1 \%$ de probabilidade pelo teste F; ns: Não significativo a $5 \%$ de probabilidade pelo teste F. RS: Rendimento de Silagem; \%MSS: Percentual de Matéria Seca da Silagem; PMSS: Produtividade de Matéria Seca da Silagem.

De acordo com o teste $F$, a fonte de variação genótipos apresentou diferença significativa a $1 \%$ de probabilidade para as variáveis RS e PMSS. Para a fonte de variação sistemas de cultivo não houve diferença significativa a $5 \%$ de probabilidade para todas as variáveis. A fonte de variação estrutura da planta apresentou diferença significativa a $5 \%$ de probabilidade para a variável RS e diferença significativa a $1 \%$ de probabilidade para as variáveis \%MSS e PMSS. Quanto às interações $\mathrm{G} \times \mathrm{C}, \mathrm{S} \times \mathrm{Ce} \mathrm{G} \times \mathrm{S} \times \mathrm{C}$, todas as variáveis foram não significativas a $5 \%$ de probabilidade, ou seja, o comportamento dos genótipos de milho não sofreu influência dos sistemas de cultivo e das características estruturais das plantas e vice-versa.

Conforme Ferreira (2006), os coeficientes de variação apresentaram ótima precisão experimental para a variável \%MSS $(5,08 \%)$, precisão experimental aceitável para RS (17,53 t ha-1) e valor elevado para PMSS $\left(20,61 \mathrm{t} \mathrm{ha}^{-1}\right)$.

$\mathrm{Na}$ Tabela 5 encontram-se as comparações das médias dos quatro genótipos de milho para as variáveis: Rendimento de Silagem (RS); Percentual de Matéria Seca da Silagem (\%MSS) e Produtividade de Matéria Seca da Silagem (PMSS), avaliadas pelo teste de Tukey a $5 \%$ de probabilidade.

Tabela 5. Médias dos genótipos para os caracteres avaliados para silagem. Rio Largo-AL, 2015/2016.

$\begin{array}{cccc}\text { Genótipos } & \text { RS }\left(\mathrm{t} . \mathrm{h}^{-1}\right) & \% \text { MSS } & \text { PMSS }\left(\mathrm{t} . \mathrm{a}^{-1}\right) \\ \text { Alagoano } & 25,16^{\mathrm{a}} & 34,58 \mathrm{a} & 8,70^{\mathrm{a}} \\ \text { Viçosense } & 25,77^{\mathrm{a}} & 35,12 \mathrm{a} & 9,05^{\mathrm{a}} \\ \text { Nordestino } & 24,22^{\mathrm{a}} & 37,04 \mathrm{a} & 8,97^{\mathrm{a}} \\ \text { Cruzeta } & 12,88 \mathrm{~b} & 34,62 \mathrm{a} & 4,45 \mathrm{~b} \\ \text { Média } & & 35,34 & \\ \Delta(5 \%) & 4,28 & 3,99 & 1,75\end{array}$

Médias seguidas pela mesma letra nas colunas não diferem estatisticamente entre si pelo teste de Tukey a $5 \%$ de probabilidade. RS: Rendimento de Silagem; \%MSS: Percentual de Matéria Seca da Silagem; PMSS: Produtividade de Matéria Seca da Silagem. 
Para todas as variáveis os genótipos do SMGP (Alagoano, Viçosense e Nordestino) apresentaram ótimo desempenho e não diferiram significativamente, sendo superiores para a maioria das variáveis quando comparados à variedade Cruzeta.

Com relação à variável RS os genótipos Viçosense $\left(25,77 \mathrm{t} \mathrm{ha}^{-1}\right)$, Alagoano $\left(25,16 \mathrm{t} \mathrm{ha}^{-1}\right) \mathrm{e}$ Nordestino $\left(24,22 \mathrm{t} \mathrm{ha}^{-1}\right)$ não apresentaram diferença significativa e foram superiores à variedade Cruzeta $\left(12,88\right.$ tha $\left.^{-1}\right)$.

Para a variável \%MSS não houve diferença significativa para todos os genótipos, apresentando uma média geral de $35,34 \%$ de matéria seca da silagem. Esse resultado foi superior quando comparado com Rosa et al. (2004), em avaliação do valor nutritivo da silagem de híbridos de milho, e Santos (2009) avaliando o potencial forrageiro e valor nutricional de variedades de milho para silagem no semiárido.

Lima et al. (2007) consideram que o teor mínimo de matéria seca da silagem para que a fermentação se processe em condições adequadas é de $28 \%$. Todos os genótipos avaliados no presente trabalho apresentaram médias para a variável \%MSS acima do percentual sugerido pelos referidos autores, indicando que tais genótipos apresentam condições adequadas para uma boa fermentação.

Em relação à variável PMSS os genótipos Viçosense $\left(9,05 \mathrm{t} \mathrm{ha}{ }^{-1}\right)$, Nordestino $\left(8,97 \mathrm{t} \mathrm{ha}^{-1}\right) \mathrm{e}$ Alagoano $\left(8,70\right.$ t.ha $\left.^{-1}\right)$ não apresentaram diferença significativa e foram superiores à variedade Cruzeta $\left(4,45\right.$ t ha- $\left.^{-1}\right)$.

Oliveira et al. (2006), avaliando o comportamento agronômico e qualidade de silagem das 20 principais cultivares comerciais de milho disponíveis no mercado alagoano nos municípios de Rio Largo e
Teotônio Vilela por três anos consecutivos (2002, 2003, 2004), obtiveram médias de produção de matéria seca da silagem para todos os híbridos nos dois municípios semelhantes aos genótipos Viçosense, Nordestino e Alagoano.

Com médias gerais de 25,05 $\mathrm{t} \mathrm{ha}^{-1}$ para RS, $35,58 \%$ para \%MSS e 8,90 t ha-1 para PMSS, os genótipos do SMGP (Alagoano, Viçosense e Nordestino) apresentaram resultados inferiores quando comparados com Silva Júnior (2015) avaliando os mesmos genótipos para produção de silagem. Os baixos valores obtidos para tais variáveis quando comparados com o referido autor podem ser justificados pelas diferentes densidades populacionais de plantas utilizadas em relação aos trabalhos. Em populações de 125.000 plantas.ha $^{-1}$ e 166.667 plantas.ha-1 ${ }^{-1}$ Silva Júnior (2015) obteve médias de $48,49 \mathrm{t} \mathrm{ha}^{-1}$ para RS, 39,47\% para \%MSS e $21,81 \mathrm{t}$ ha $^{-1}$ para PMSS.

O cultivo em consórcio não é apenas avaliado pela produção, mas sim pelo composto produtivo, que vai desde a produção das duas espécies vegetais, como produção equivalente, até as vantagens dentro do ecossistema (Carvalho et al., 2016). Assim sendo, na comparação com o sistema de monocultivo é fundamental que seja levada em consideração a produção do feijão e da silagem do milho, além de das vantagens de segurança para o produtor que terá mais de uma opção de produto sendo produzido na mesma área.

$\mathrm{Na}$ Tabela 6 constam as médias das duas características estruturais da planta de milho, com e sem espiga primária, para as variáveis: Rendimento de Silagem (RS); Percentual de Matéria Seca da Silagem (\%MSS) e Produtividade de Matéria Seca da Silagem (PMSS), avaliados pelo teste de $\mathrm{F}$ a $5 \%$ de probabilidade.

Tabela 6. Médias das características estruturais da planta para os caracteres avaliados para silagem. Rio LargoAL, 2015/2016.

\begin{tabular}{cccc}
\hline Características estruturais da planta & RS (t.ha-1 ${ }^{-1}$ & $\% M S S$ & PMSS $\left(\right.$ t.ha $\left.a^{-1}\right)$ \\
\hline Com espiga primária & $23,52^{\mathrm{a}}$ & $37,10 \mathrm{a}$ & $8,72^{\mathrm{a}}$ \\
\hline Sem espiga primária & $20,50 \mathrm{~b}$ & $33,58 \mathrm{~b}$ & $6,88 \mathrm{~b}$ \\
\hline
\end{tabular}

Médias seguidas pela mesma letra nas colunas não diferem estatisticamente entre si pelo teste $\mathrm{F}$ a $5 \%$ de probabilidade. RS: Rendimento de Silagem; \%MSS: Percentual de Matéria Seca da Silagem; PMSS: Produtividade de Matéria Seca da Silagem. 
Com médias de 23,52 t ha-1 para RS, 37,10\% para \%MSS e 8,72 t ha-1 para PMSS, a estrutura da planta com a presença da espiga primária se mostrou superior para todas as variáveis quando comparada com a estrutura da planta sem a espiga primária. Tais resultados comprovam que a presença da espiga primária é fundamental para uma maior produção de silagem contribuindo para atender a demanda do animal com uma alimentação de maior qualidade.

$\mathrm{Na}$ Tabela 7 encontram-se as médias dos sistemas de cultivo, monocultivo e consorciado, para as variáveis: Rendimento de Silagem (RS); Percentual de Matéria Seca da Silagem (\%MSS) e Produtividade de Matéria Seca da Silagem (PMSS), avaliados pelo teste $\mathrm{F}$ a $5 \%$ de probabilidade.

Tabela 7. Médias dos sistemas de cultivo para os caracteres avaliados para silagem. Rio Largo-AL, 2015/2016.

\begin{tabular}{cccc}
\hline Sistema de cultivo & RS (t.ha-1) & \%MSS & PMSS (t.ha- $\left.{ }^{-1}\right)$ \\
\hline Monocultivo & $22,20 \mathrm{a}$ & $34,93 \mathrm{a}$ & $7,75^{\mathrm{a}}$ \\
\hline Consórcio & $21,81 \mathrm{a}$ & $35,75 \mathrm{a}$ & $7,79^{\mathrm{a}}$ \\
\hline Média & 22,00 & 35,34 & 7,77
\end{tabular}

Médias seguidas pela mesma letra nas colunas não diferem estatisticamente entre si pelo teste $\mathrm{F}$ a $5 \%$ de probabilidade. RS: Rendimento de Silagem; \%MSS: Percentual de Matéria Seca da Silagem; PMSS: Produtividade de Matéria Seca da Silagem.

Para todas as variáveis não houve diferença significativa em relação aos sistemas de cultivo, apresentando médias gerais de $22,00 \mathrm{t}$ ha-1 para a variável RS, 35,34\% para a variável \%MSS e 7,77 t ha $^{-1}$ para a variável PMSS. Com isso, observou-se que o sistema de cultivo consorciado do milho com a cultura do feijão não influenciou no potencial forrageiro dos genótipos de milho avaliados para produção e qualidade da silagem quando comparado com 0 sistema de monocultivo.

De modo geral o sistema de consórcio é recomendadoparaaproveitamento daárea, principalmente por não diminuir a produtividade em comparação com o sistema de monocultivo, dessa forma em uma mesmaárea é possivel produzir duas espécies vegetais com eficiência. Para maximizar a eficiência do consórcio é fundamental que as variedades sejam adaptadas ao sistema, de modo que, nesse trabalho os genótipos Nordestino, Alagoano e Viçosense apresentaram alto potencial forrageiro nos dois sistemas de cultivo.

\section{REFERÊNCIAS BIBLIOGRÁFICAS}

Aguiar, A.T.E.; Duarte, D.P.; Sawazaki, E.; Paziani, S.F. Milho para silagem. Boletim do Instituto Agronômico de Campinas (IAC), 2014, 200, 279p.

Carvalho, I.D.E.; Ferreira, P.V.; Silva Júnior, A.B.; Oliveira, F.S.; Carvalho, A.P.V.; Santos, P.R. Análise produtiva de genótipos de milho verde consorciados com feijão. Horticultura Brasileira, 2016, 34, 4, 593-599.

Cordeiro, L.A; Cequine, L. Avaliação de cultivares de milho para produção de silagem em área comercial em Unaí-MG. Revista Factu Ciência, 2008, 15.

Costa, A.S.; Silva, M.B. Sistemas de consórcio milho feijão para a região do vale do rio doce, Minas gerais. Ciência Agrotécnica, 2008, 32, 2, 663-667.

Cuenca, M.A.G.; Nazário, C.C.; Mandarino, D.C. Características e evolução da cultura do milho no Estado de Alagoas entre 1990 e 2003. Embrapa, 2005.

DUPONT. Análise bromatológica da silagem. Portal DuPont Pioneer, 2016. URL (http:// www.pioneersementes.com.br/milho/silagem/ analisebromatologica) (Acesso em 24 jul. 2016).

Estênio, M.A. Produção de milho-verde e grãos consorciados com leguminosas em sistemas de plantio direto orgânico. Dissertação, 64 p., Viçosa, MG, 2014.

Ferrari JR., E.; POSSENTI, R.A.; LIMA, M.L. Características, composição química e qualidade de silagens de oito cultivares de milho. Boletim de Indústria Animal, 2005, 62, 1, 19-27.

Ferreira, P.V. Melhoramento de plantas: princípios e perspectivas. Maceió: EDUFAL, v.1, 110p. 2006. 
Ferreira, D.F. Programa SISVAR: sistema de análise de variância. Versão 4,6 (Build 6,0), Lavras, DEX/UFLA, 2003.

Ferreira, P.V. Estatística experimental aplicada à Agronomia.3ª ed., 422p. Maceió: EDUFAL, 2000.

Kim, S.C.; Adesogan, A.T. Influence of ensiling temperature, simulated rainfall, and delayed sealing on fermentation characteristics and aerobic stability of corn silage. Journal Dairy Science, 2006, 89, 8, 3122-3132.

Lauer, J. Harvesting silage at the correct moisture. Wisconsin Crop Manager, v,3, n,24, p,142-143, 1996. URL (http://corn.Agronomy.wisc.edu/Publications/ WCM/1996/SHARVEST96.htm) (05 dez. 2016).

Lima, J.A.; Evangelista. A.R.; Lopes, F.; Junior, E.F.; Nardon, R.F.; Otsuk, P.l; Ishikawa, H.G.; Aguirre, J.; Turco, P.H.; Filho, J.A. Composição química da silagem de plantas de milho com e sem espigas. B. Indústr. anim., Nova Odessa, 2007, 64, 3, 207-212.

Madalena, J.A.S.; Ferreira, P.V.; Cunha, E.L.; Xavier, J.L.; Linhares, P.C.F. Seleção de genótipos de milho (Zea mays L.) submetidos a quatro densidades de semeadura no município de Rio Largo-AL. Revista Caatinga, 2009, 22, 1, 48-58.

MAPA(Ministério daAgricultura, PecuáriaeAbastecimento). $5^{\circ}$ fórum do milho, Expo direto Cotrijal, 2013.

Oliveira, J.S.; Sobrinho, F.S.; Miranda, C.A.; Santiago, A.D.; Santos, D.M. Cultivares de milho para silagem - resultados das safras 2002, 2003, 2004 no leste alagoano. Circular técnico 86, Embrapa. Juíz de ForaMG, 2006.

Pereira, J.R. O mercado de silagem de milho no Brasil. Portal Milk Point, 2013. URL (http://www.milkpoint. com.br/mypoint/253066/p_o_mercado_de_silagem_ de_milho_no_brasil_cadeia_produtiva_graos_milho_ silagem_mercado_5217.aspx). (25 jul. 2016).

Rosa, J.R.; Silva, J.H.; Restle, J.; Pascoal, L.L.; Brondani, I.L.; Filho, D.C.; Freitas, A.K. Avaliação do Comportamento Agronômico da Planta e Valor Nutritivo da Silagem de Diferentes Híbridos de Milho (Zea mays, L.). Revista Brasileira de Zootecnia, 2004, 33, 2, 302-312.
Sangoi, L.; Schweitzer, C.; Schmitt, A.; Pacoli Júnior, G.J.; Vargas, V.P.; Vieira, J.; Siega, E.; Carniel, G.. Perfilhamento e prolificidade como características estabilizadoras do rendimento de grãos do milho, em diferentes densidades. Revista Brasileira de Milho e Sorgo, 2010, 9, 3, 254-265.

Santos, R.D. Potencial forrageiro e valor nutricional de variedades de milho para silagem no semiárido. Dissertação de Mestrado em Ciência Animal. 90 p., Universidade Federal do Vale do São Francisco, 2009.

Santos, H.G.; Jacomine, P.K.T.; Anjos, L.H.C.; Oliveira, V.A.; Oliveira, J.B; Lumbreras, J.F. Cunha, T. J. F. Sistema Brasileiro de Classificação de Solos. 2ed. 306p. Rio de Janeiro: EMBRAPA SOLOS. 2006.

SHMIDT, P. Entrevista sobre produção de silagem de milho. Portal Ensilagem, Revista DBO Mundo do Leite, 2011. URL (http://www.ensilagem.com.br/ entrevistasobreproducaodesilagemdemilho/). (25 jul. 2016).

Silva Júnior, A. B.; Ferreira, P. V.; Cunha, J. X. L.; Lira, R. C.; Carvalho, I. D. E. Desempenho de genótipos de milho em sistemas de cultivo superadensados para produção de grãos. Revista Agrotecnologia, 2015, 6, 1, 13-26.

Silva Júnior, A. B. Desempenho de genótipos de milho sob diferentes espaçamentos entre linhas para múltipla aptidão. Dissertação de Mestrado em Agronomia (Produção Vegetal). p.49, Universidade Federal de Alagoas, Rio Largo - AL, 2015.

Souza, J.L.; Filho, G.M.; Lyra, R.F.; Teodoro, I.; Santos, E.A.; Silva J.L.; Silva, P.R.; Cardim, A.H.; Amorim, A.C. Análise da precipitação pluvial e temperatura do ar na região do Tabuleiro Costeiro de Maceió, AL, período 1972-2001. Revista brasileira de Agrometeorologia, 2004, 11, 2, 131-141.

Teixeira, I.R.; Mota, J.H.; Silva, A.G. Consórcio de hortaliças. Semina: Ciências Agrárias, 2005, 26, 24, 507-514.

Turco, G.M. Produção e composição física da planta de milho para silagem, cultivado em dois níveis de adubação, dois espaçamentos entre linhas e duas densidades de plantio. Dissertação de Mestrado em Agronomia (Produção Vegetal). Universidade Estadual do Centro-Oeste. Guarapuava-PR, 2011. 